\title{
Manasement of three impacted teeth detected early
}

\author{
P. Guézénec \\ Qualified Specialist in Dento facial Orthopedics. Private practice in Saint-Brieuc
} ABSTRACT

Impacted teeth often represent an important therapeutic hazard in a treatment, both in terms of the uncertainty of the result, the quality of the periodontium, and the duration of the treatment.

A bioprogressive approach can resolve the problem and preserve the teeth in a healthy environment, avoiding subsequent implants

\section{INTRODUCTION}

François, aged 9 years, consulted in July 2005, with a panoramic showing a cyst that resulted in the central right maxillary incisor becoming impacted.
A resection was carried out in September 2005 (Fig. 1). François was addressed by his dentist, who mentioned the possibility of extracting 13,12 , and 11 , and to employ three implants later.

\section{CLINICAL EXAMINATION AND DIAGNOSIS}

The patient was seen again in December 2006, when he was aged 10 years and 5 months (Fig. 2). A fresh panoramic image showed the very horizontal position of 12 blocking the development of 13 and 11 (Fig. 3).
The child's record was updated in March 2007. To complete the documentation, in addition to the frontal, profile, and panoramic X-rays, a head computed tomography (CT) scan was performed for visualizing the spatial position of these three teeth (Fig. 4).

Address for correspondence:

Patrick GUÉZÉNEC,

3 bd Waldeck Rousseau, 22000, Saint-Brieuc

E-mail: odf.guezenec@wanadoo.fr

Article received: 03/01/2017. Accepted for publication: 10/02/2017.

This is an Open Access article distributed under the terms of the Creative Commons Attribution License (http://creativecommons.org/licenses/by/4.0), which permits unrestricted use, distribution, and reproduction in any medium, provided the original work is properly cited. 


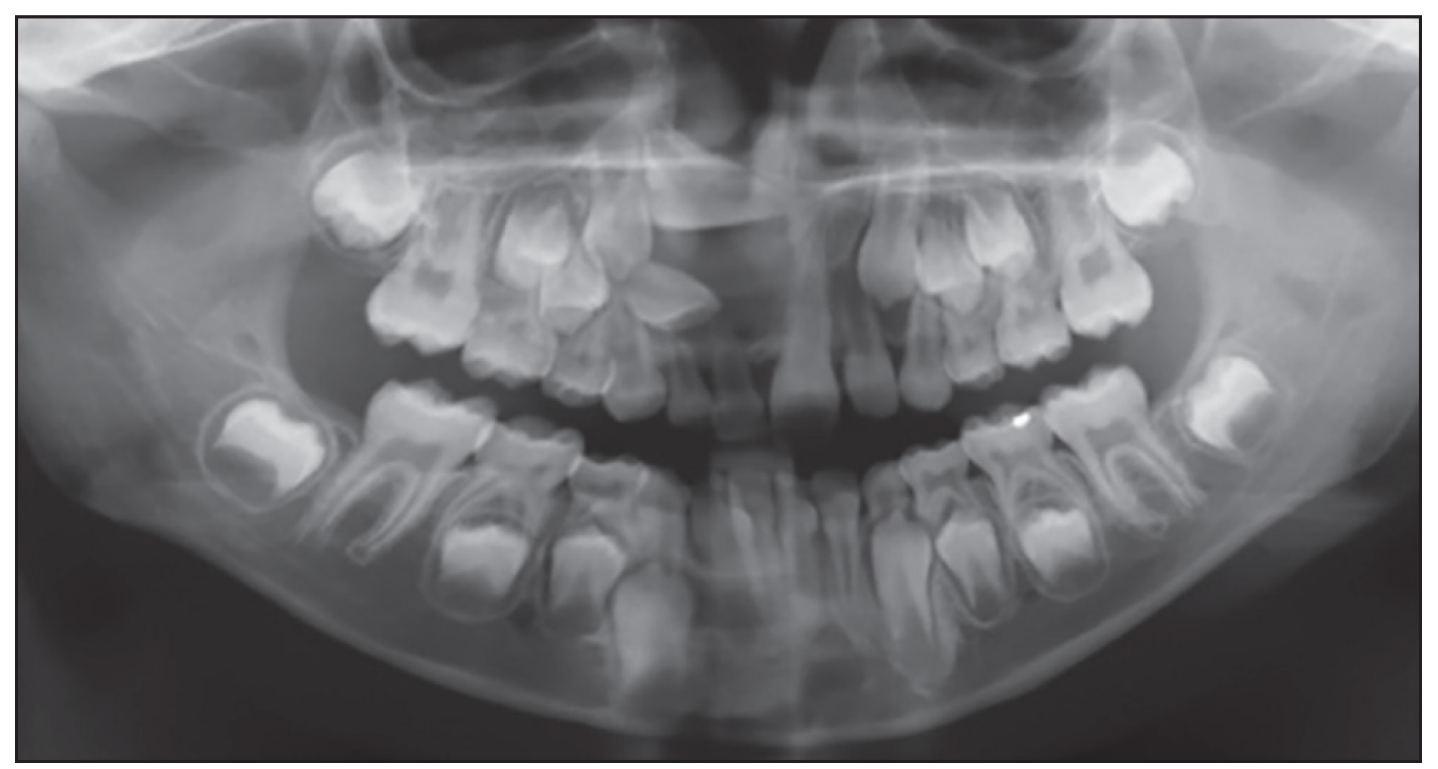

Figure 1

Pretreatment panoramic view (Sept 2005).

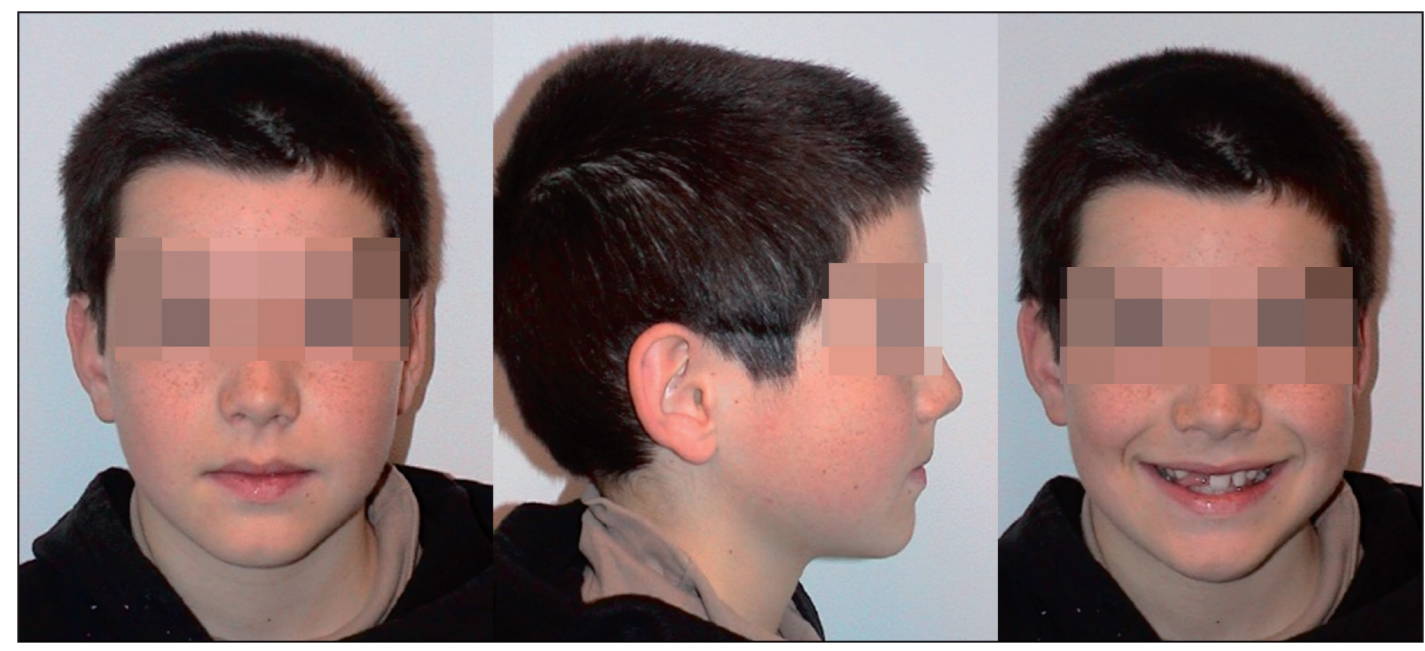

Figure 2

Initial frontal, profile and Smile views of the face (December).

The clinical examination does not show any functional problems, the child has very good dental hygiene, tonsils, and adenoids are present.

The ventilation is nasal, and Francois only refers to his "smile with holes."

From a dental point of view, he is in class I on the left and in class II on the right with an overhang of $2 \mathrm{~mm}$ and an incisive covering of $60 \%$. A mild obstruction of $2 \mathrm{~mm}$ is noted in the mandible, but the stability of 75 and 85 allows enough leeway (Fig. 5).

The centered relation and the maximum intercuspation coincide. The upper maxilla is in $\mathrm{V}$ with rotation of the 


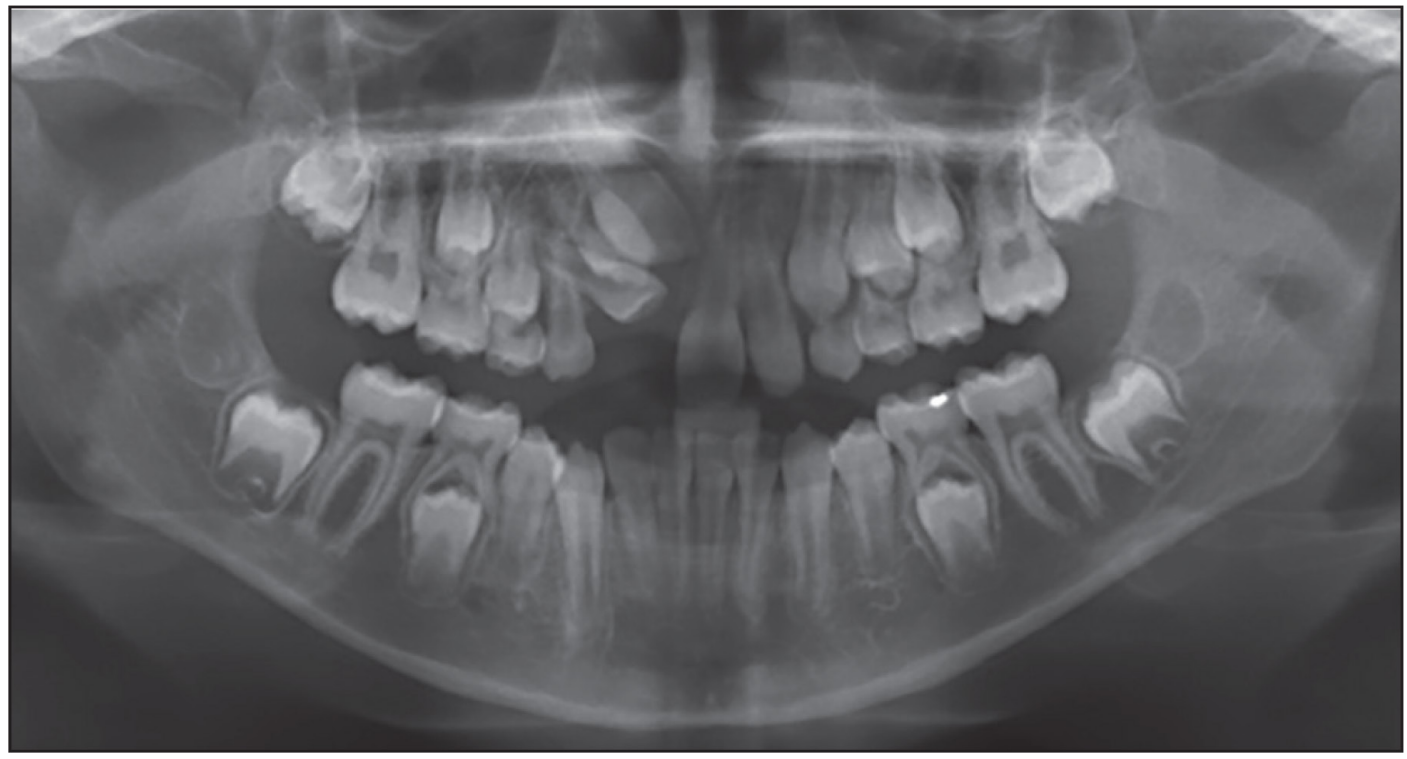

$\circlearrowleft$

Figure 3

Initial panoramic view (December).

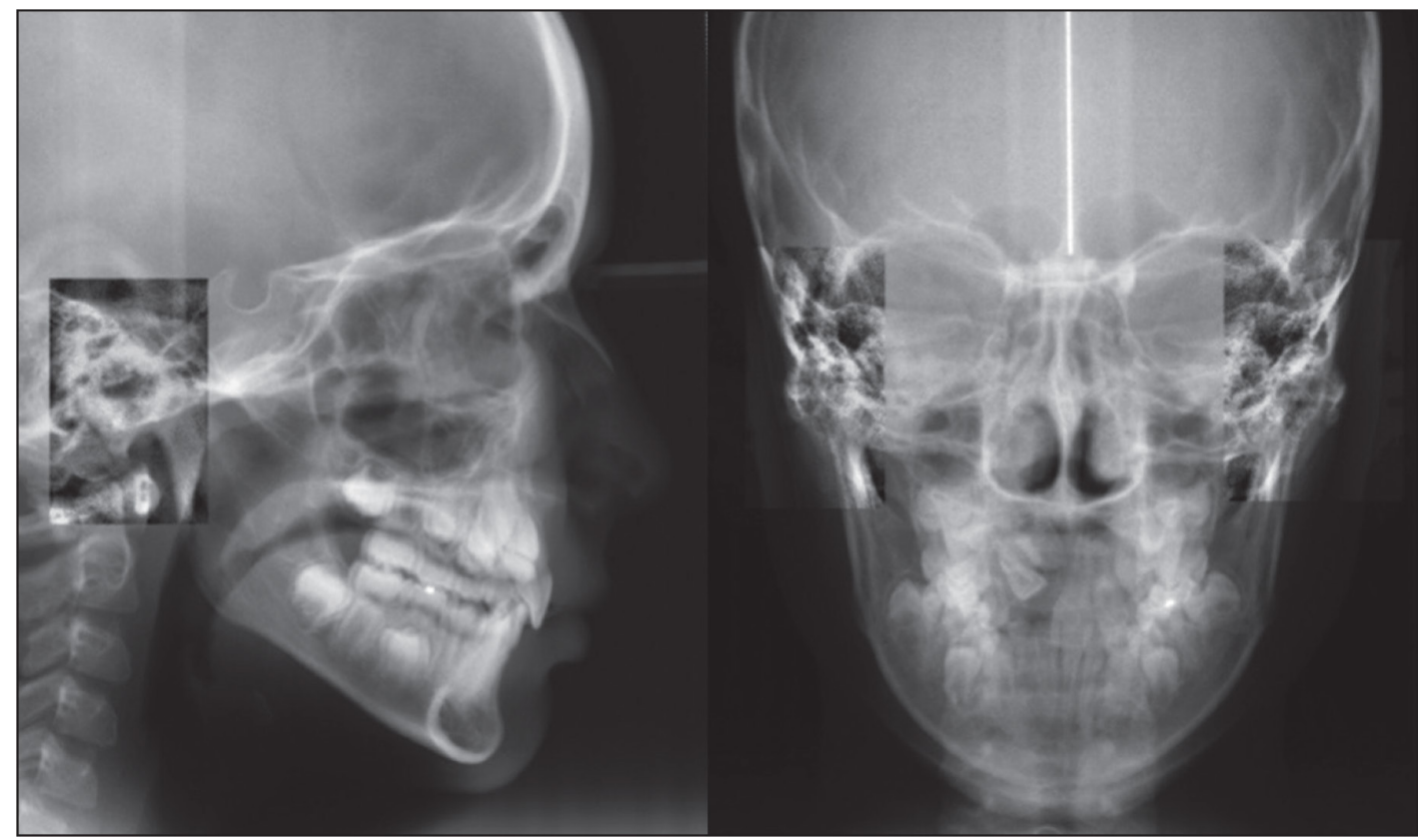

Figure 4

Initial Frontal and profile teleradiography (December). 

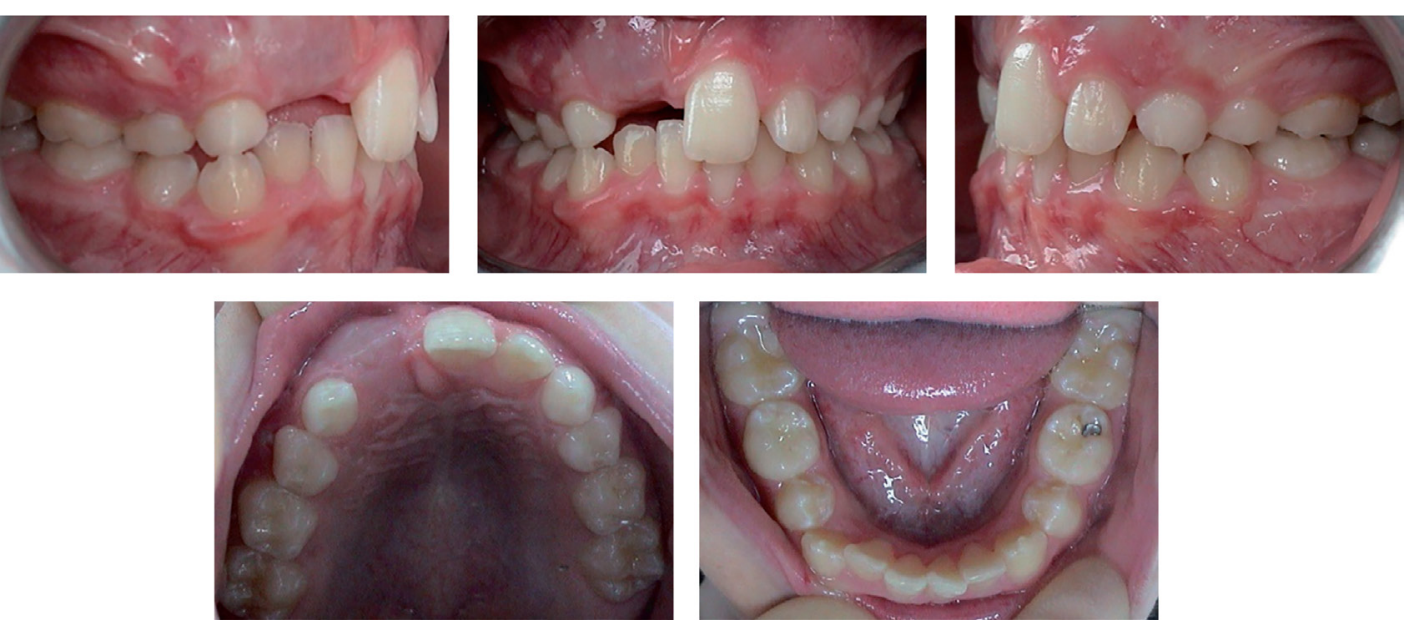

Figure 5

Initial intraoral view (March 2007).

molars, and the mandible is locked. His upper median is obviously deflected to the right by $2 \mathrm{~mm}$, his central incisor is $4 \mathrm{~mm}$ visible at rest and $9 \mathrm{~mm}$ visible when he smiles, without gingival exposure.

The movements of the TMJ show a maximum aperture of $45 \mathrm{~mm}$, a protrusion of $6 \mathrm{~mm}$, and lateralization of $7 \mathrm{~mm}$ to the right and left, without any pain or noises made by the joint.

The cooperation of the child and the parents is very good, and François has benefited from re-education therapy in the third grade for a hiss.

The profile cephalometric analysis shows meso-facial growth with a small anterior mandibular rotation, but without skeletal shift. The upper central incisors are in linguoversion, as well as the lower incisors and the analysis of the Harvold triangle shows a small mandibular insufficiency and a slight decrease in the lower section of the face. The profile is harmonious (Fig. 6)

The facial analysis highlights a superior maxillary endognathy with an intermaxillary distance of $50 \mathrm{~mm}$ instead of $58 \mathrm{~mm}$ at his age. 21 is beyond the median line, without mandibular deviation (Fig. 7).

The scanner visualizes the horizontality of 12, blocking 13 and 11, the latter being very palatal and rotating (Fig. 8).

\section{TREATMENT PLAN}

The father is provided an explanation that there is a very big risk of losing 12 during the treatment. The proposed treatment plan is as follows:

1. Upper molar anchorage with a Nance arch with loops on 16 and 26 to correct the molar rotation and ensure expansion.

2. Disimpaction of 13 and 11 , without touching 12.

3. Leveling the upper arch by reversing 13, correction of the upper median. 


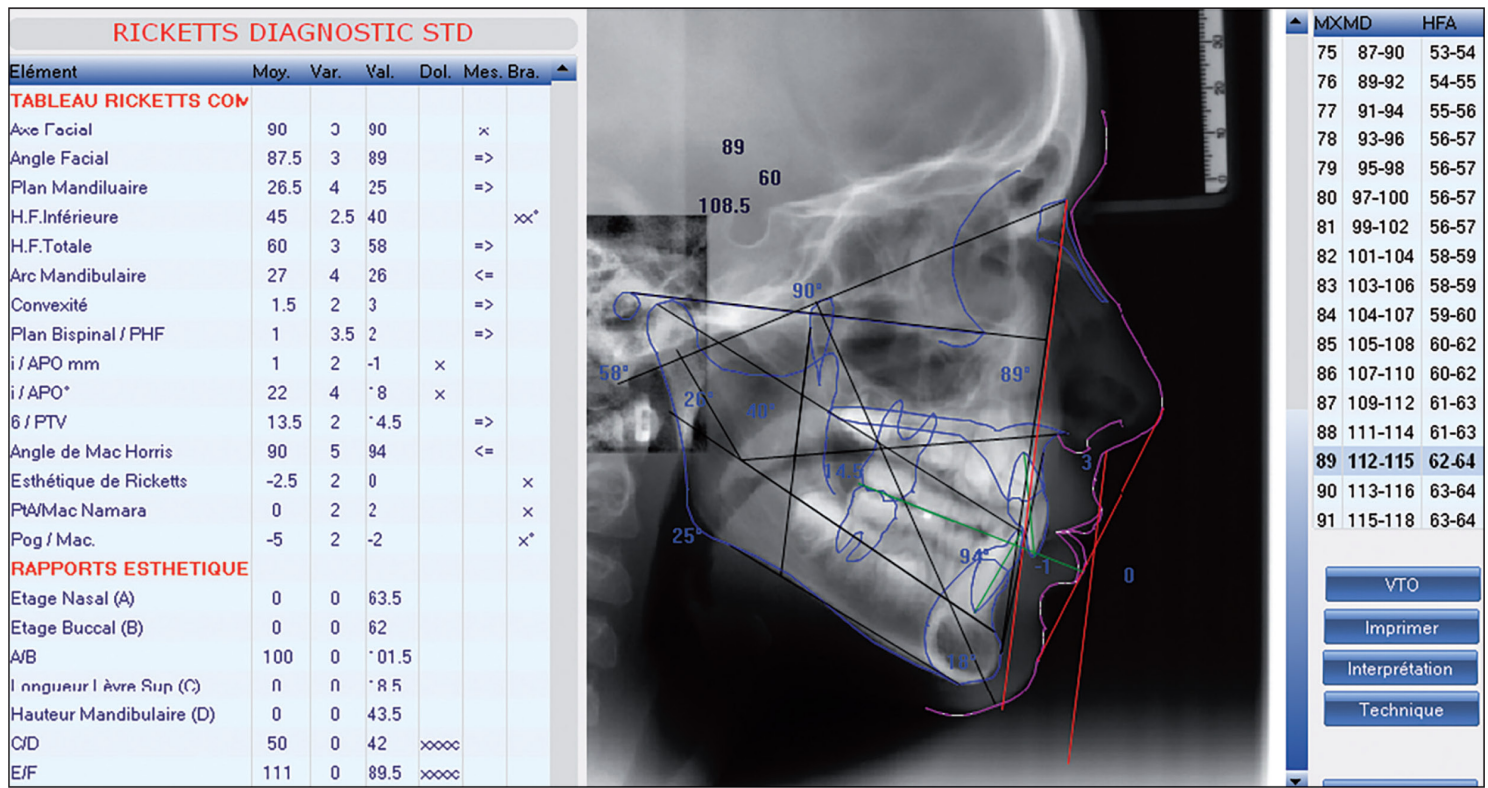

Figure 6

Rickets frontal cephalometric analysis (March 2007).

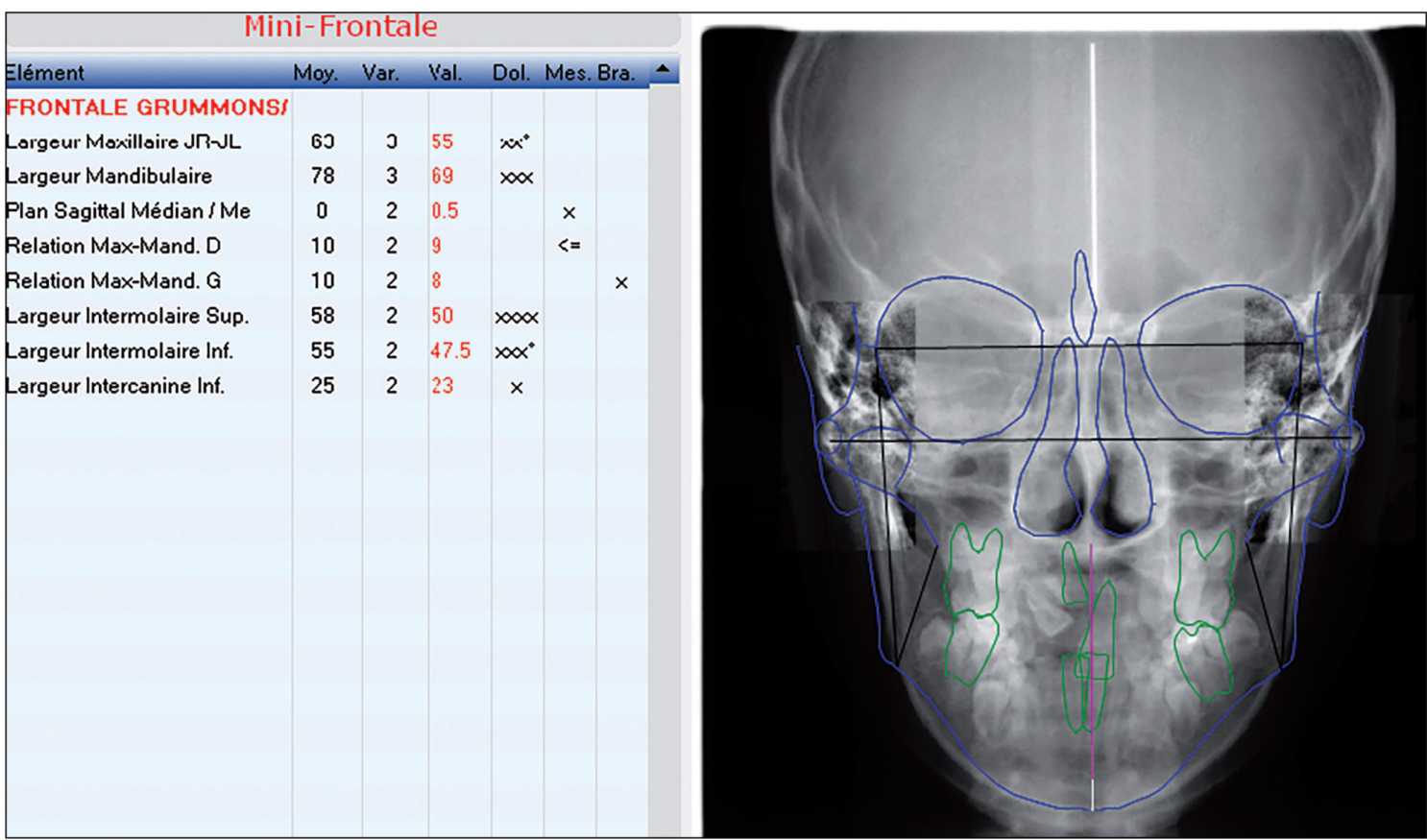

Figure 7

Initial frontal cephalometric analysis (March 2007). 

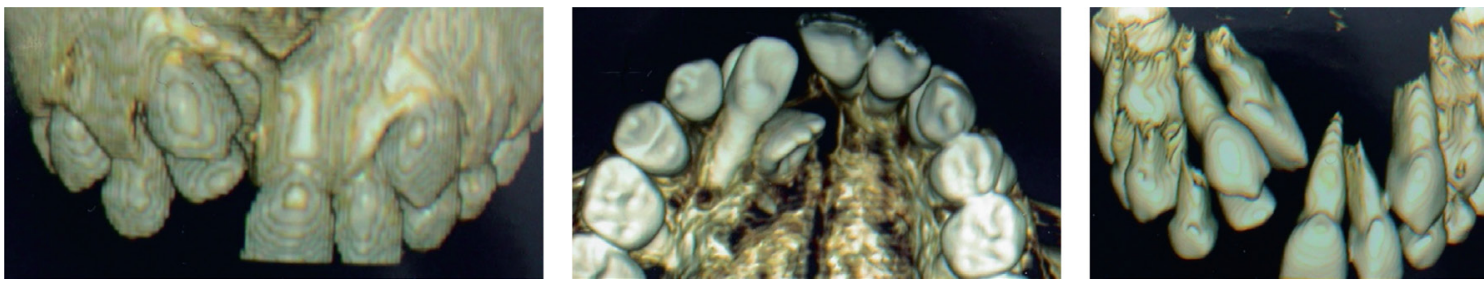

Figure 8

Initial Scan.

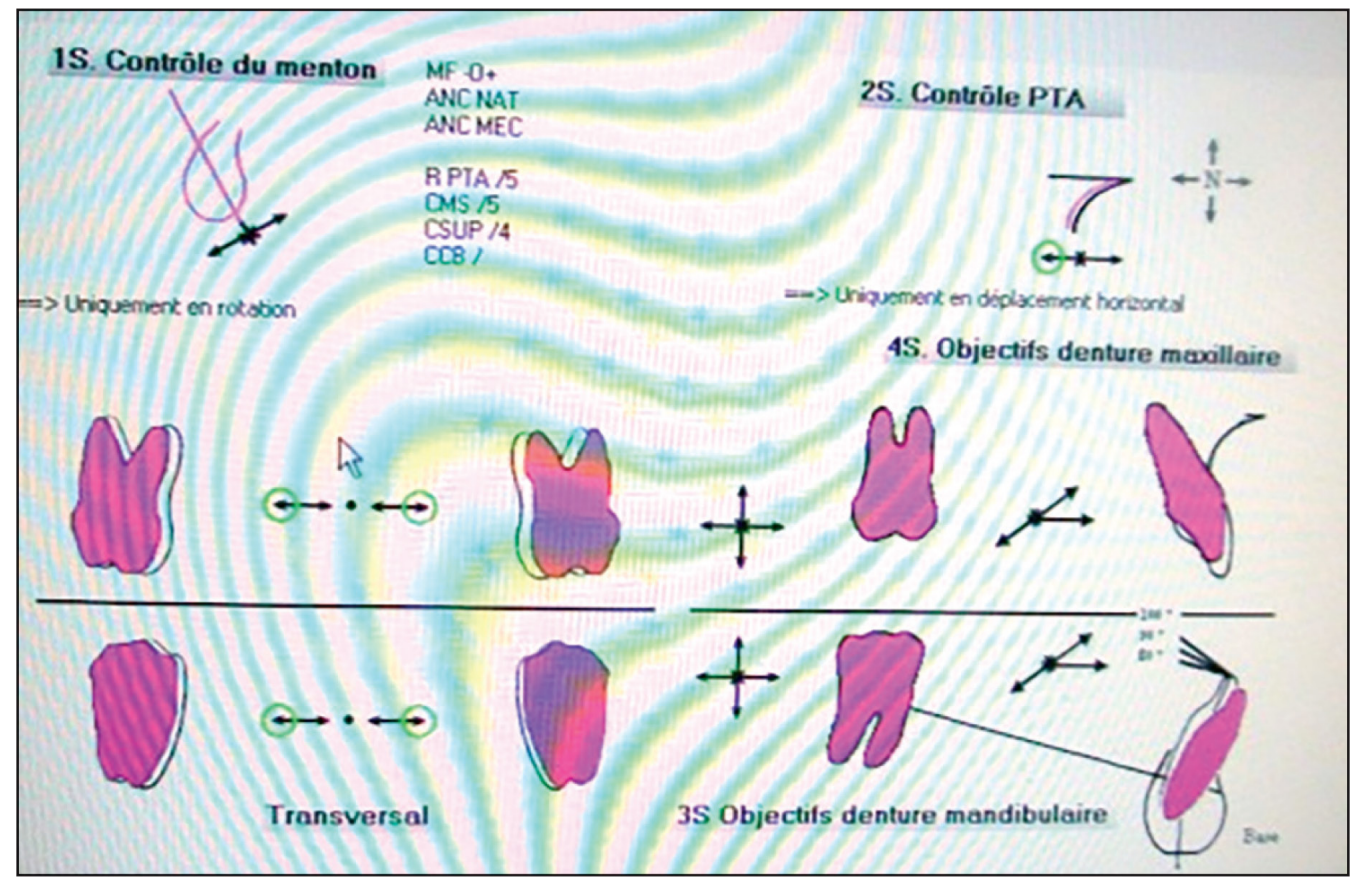

Figure 9

Treatment objectives.

4. Reassessment of retention of 12 .

5. Advanced leveling of lower incisors

6. Finish with class II intermaxillary traction on the right.

7. Elastication.
8. Superior and inferior supports

Visualization of the objectives (Fig. 9). 


\section{TREATMENT PHASES}

The treatment started in August 2007:

- September 2007: Placement of Nance arch and request for extraction of 53 and 63.

- February 2008: Attachment of the upper arch and request for disimpaction of 13 and 11 (Fig. 10). The traction on 13 and 11 is performed over a 6-month period with treatment interruptions.

- January 2009: Attachment of bracket to 11, coil spring on 12 (Figs. 11-16).

- May 2009: Attaching a lower incisor bracket on 12 for decreasing torque and setting up a very light. 012 arch (Fig. 17). Then support this tooth using radiculo-vestibular torque in front of this tooth on the base arch with intrusion (Fig. 18).
- October 2009: Base arch and lateral upper sections (Fig. 19).

- February 2010: Attachment of the mandibular arch, advancement of lower incisors in accordance with our objectives.

- March 2010: Intermaxillary class II traction on the right between 46 and 13 (Figs. 20 and 21).

- December 2010: impression taking and centered relationship for the preparation of the elastomer set up in January 2011, control X-rays for assessment (Figs. 22 and 23). The brackets of the upper incisors and canines are maintained for 3 months to ensure proper maintenance of the device. It is worn for 9 months then glued supports are placed on the upper and lower canine incisors (Figs. 24-28).
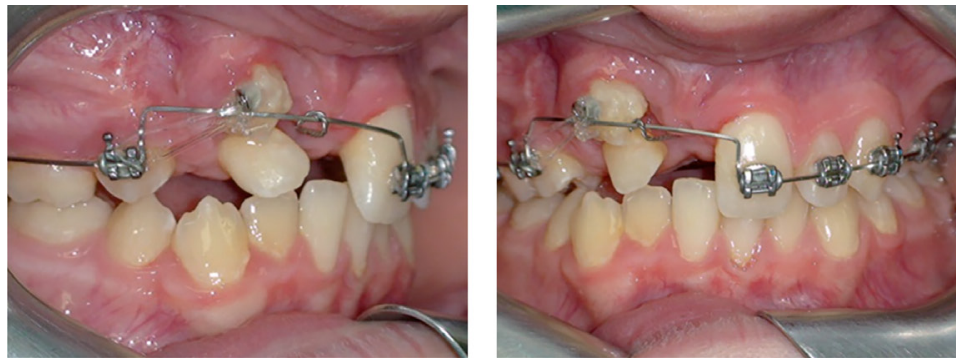

Figure 10

Intraoral View step 1.
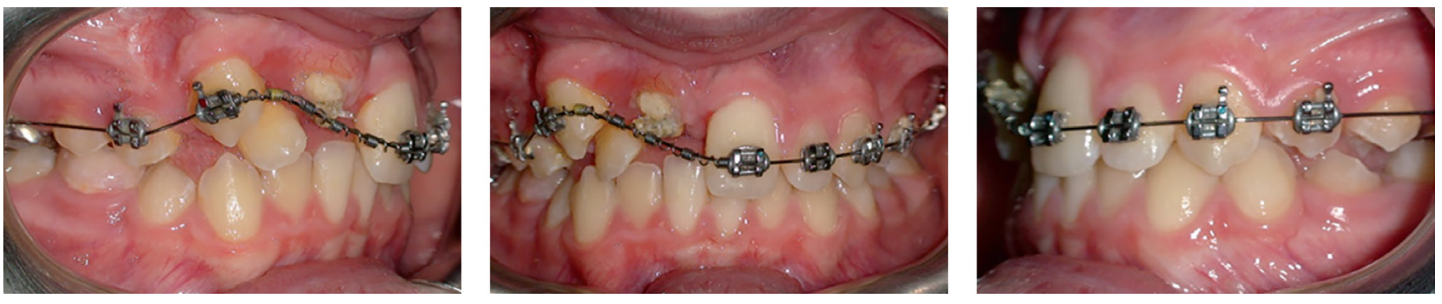

Figure 11

Intraoral View Step 2 (January 2009).

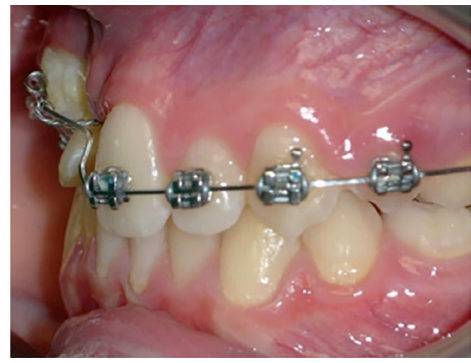

$\varangle$ 

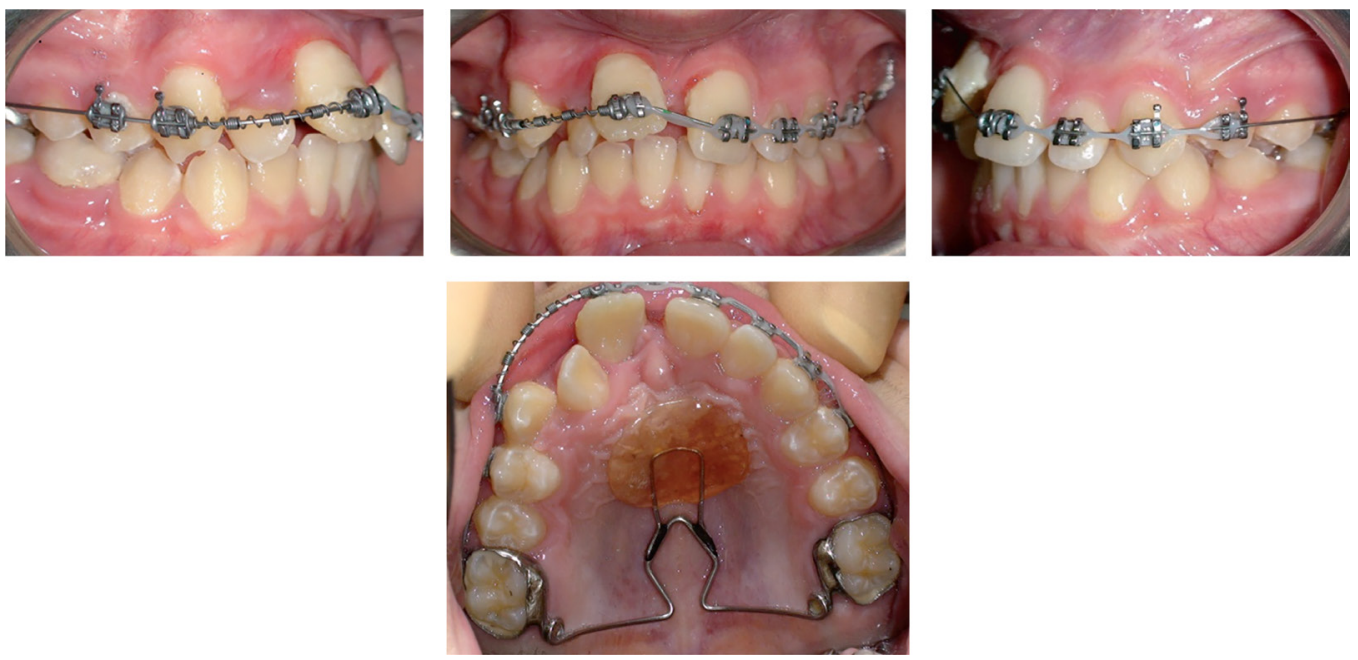

Figure 14

Intraoral view step 5.
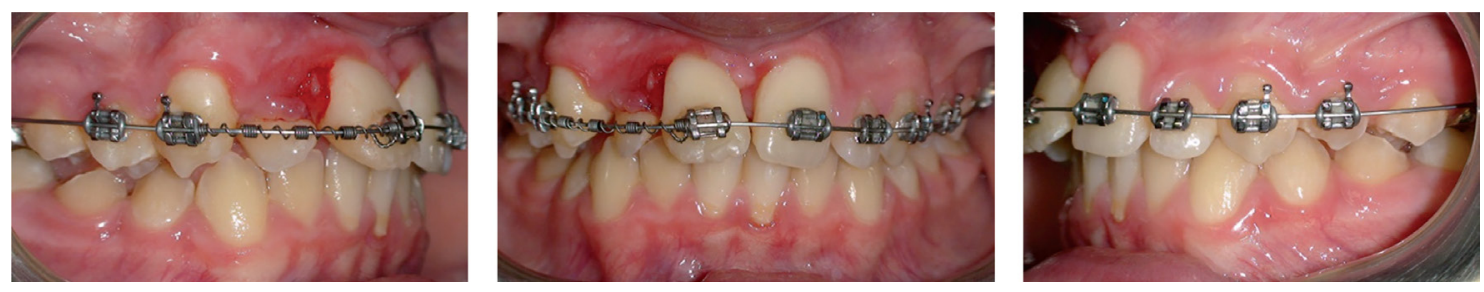

Figure 15

Intraoral view step 6.
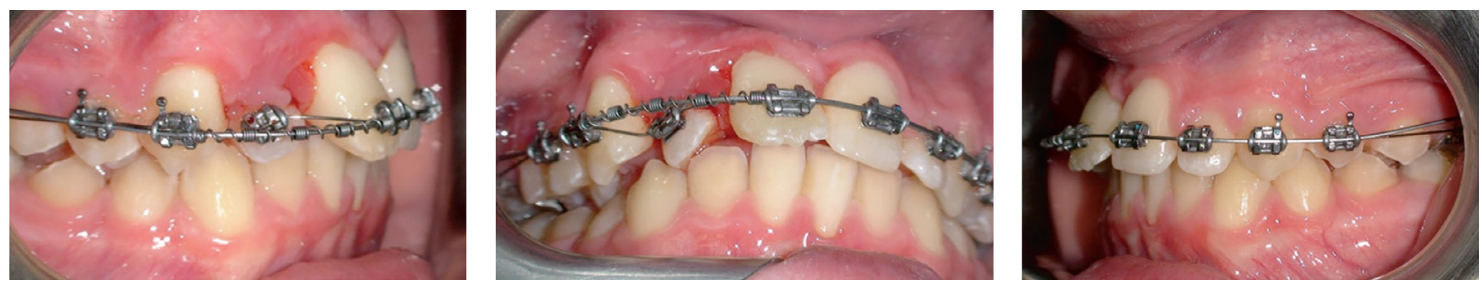

Figure 16

Intraoral view step 7. 

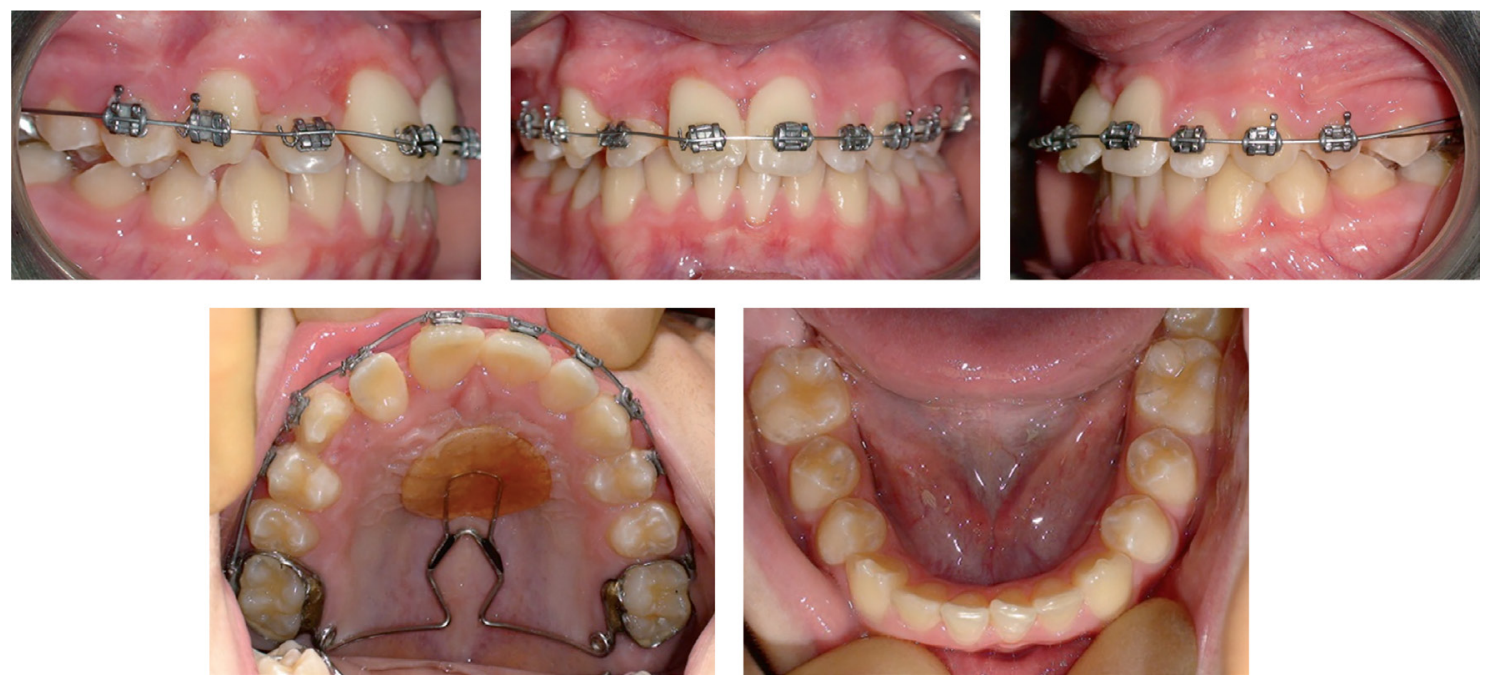

Figure 17

Intraoral View Step 8 (May 2009).

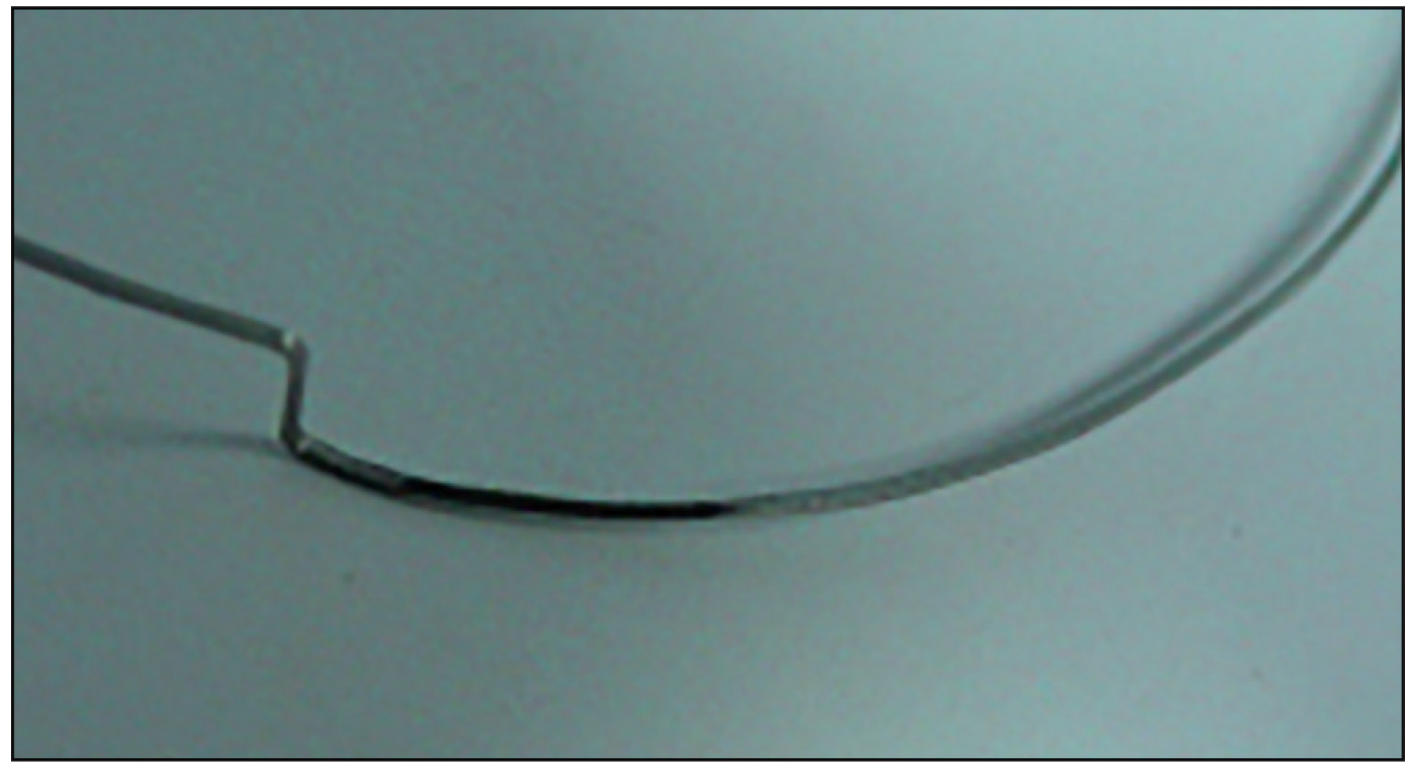

Figure 18

Base arch with radiculo-vestibular torque on 12. 

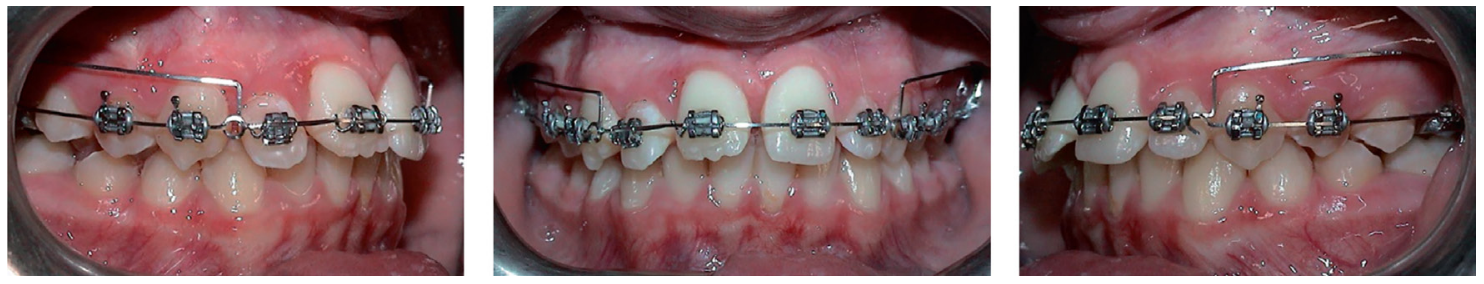

Figure 19

Intraoral view step 9.
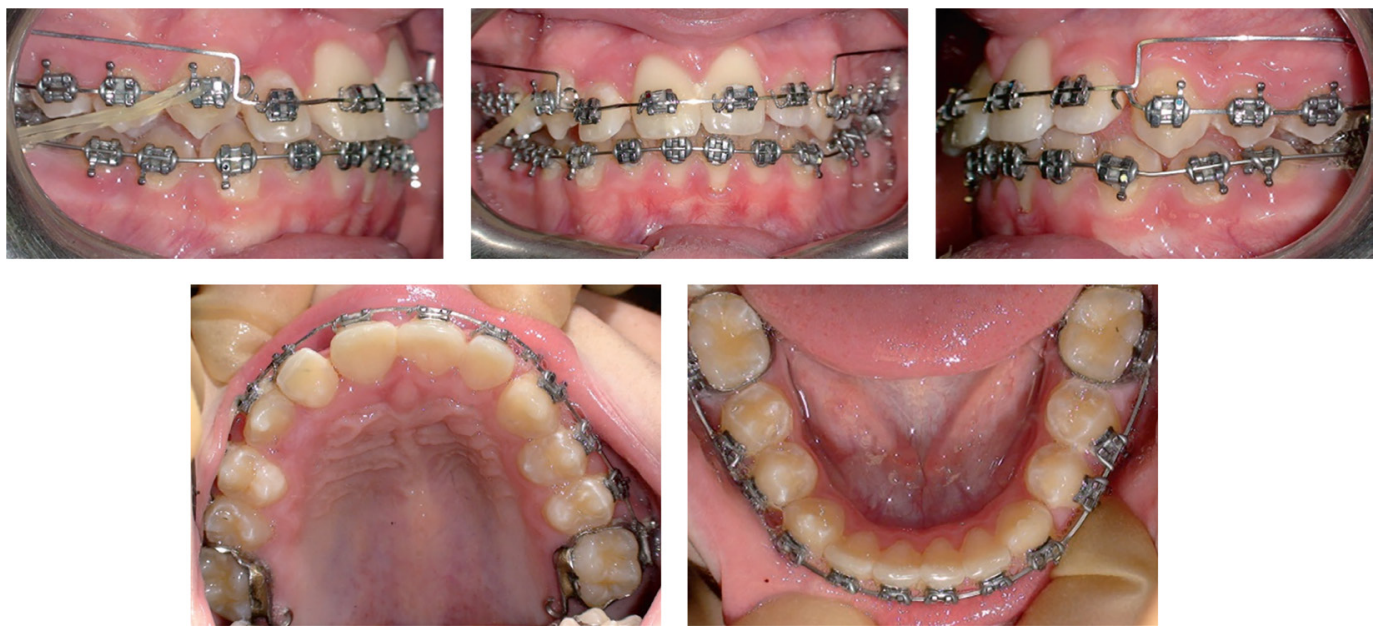

Figure 20

Class II Intermaxillary Traction (October 2009).
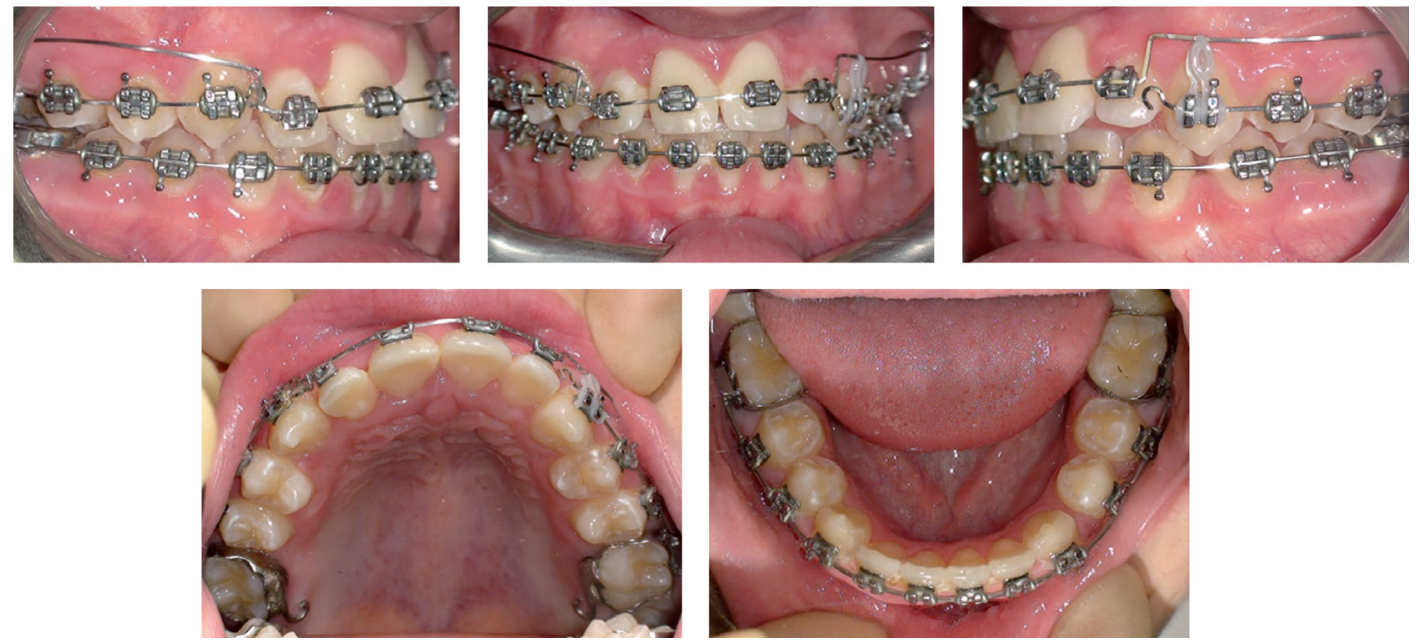

4

Figure 21

Intraoral view Step 10 (March 2010). 


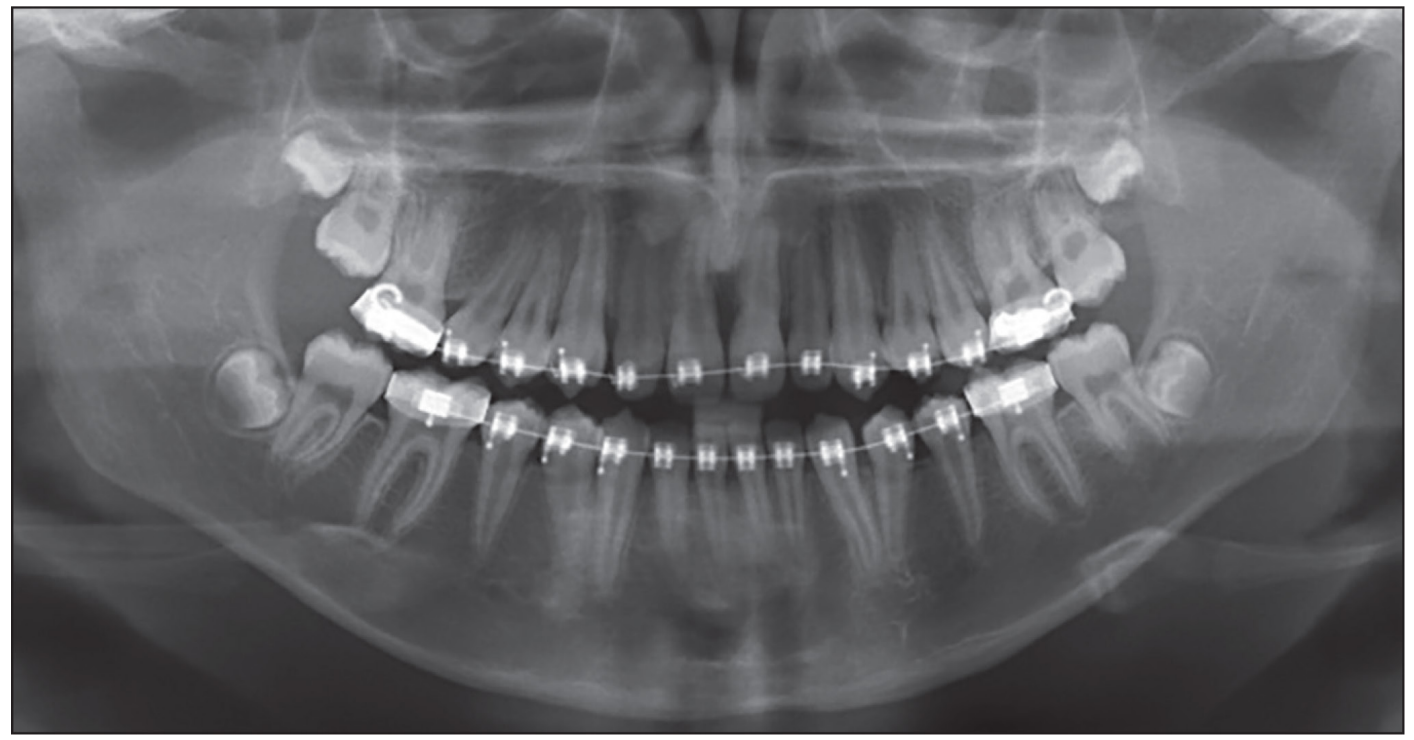

Figure 22

Control panoramic images.

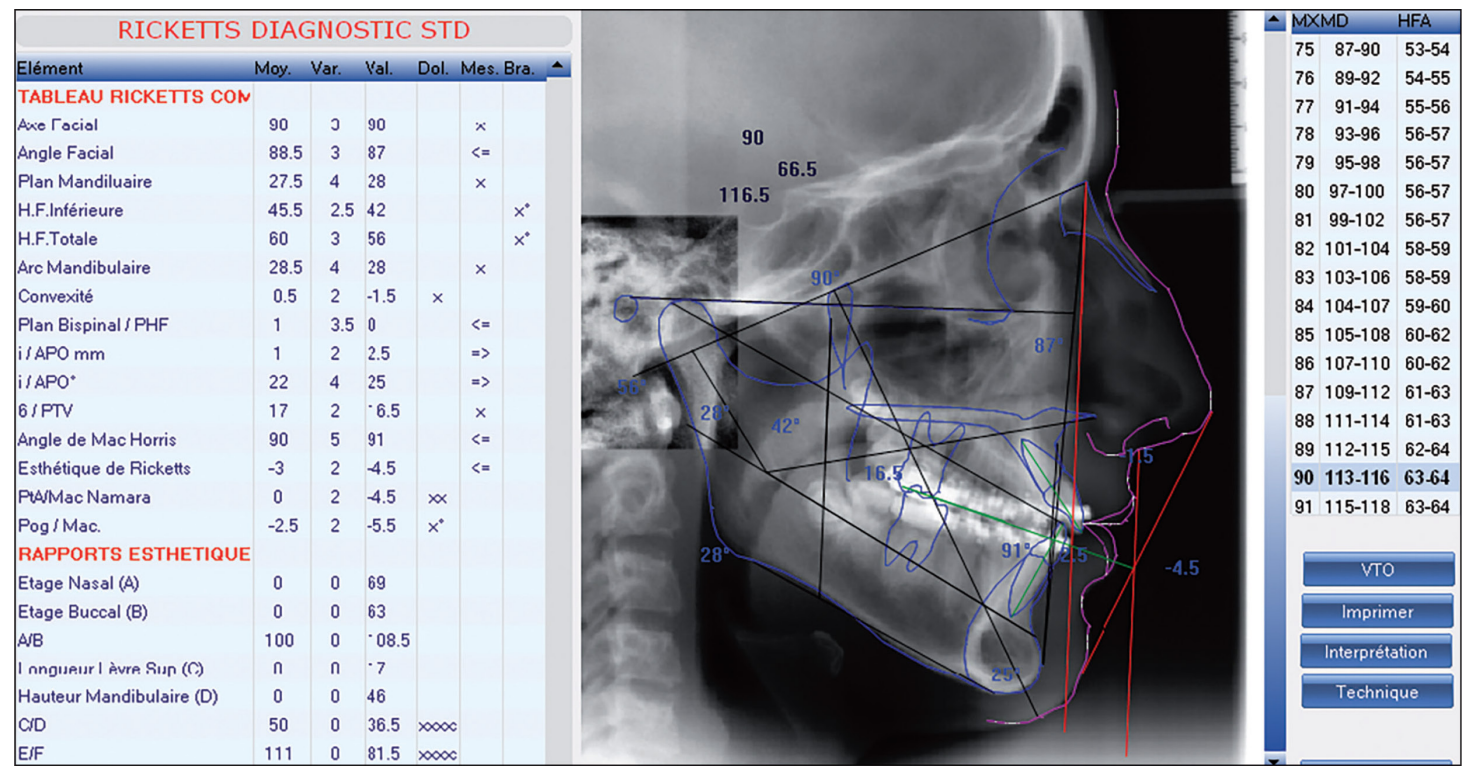

Figure 23

Profile radiological assessment in order to carry out the elastomer treatment. 

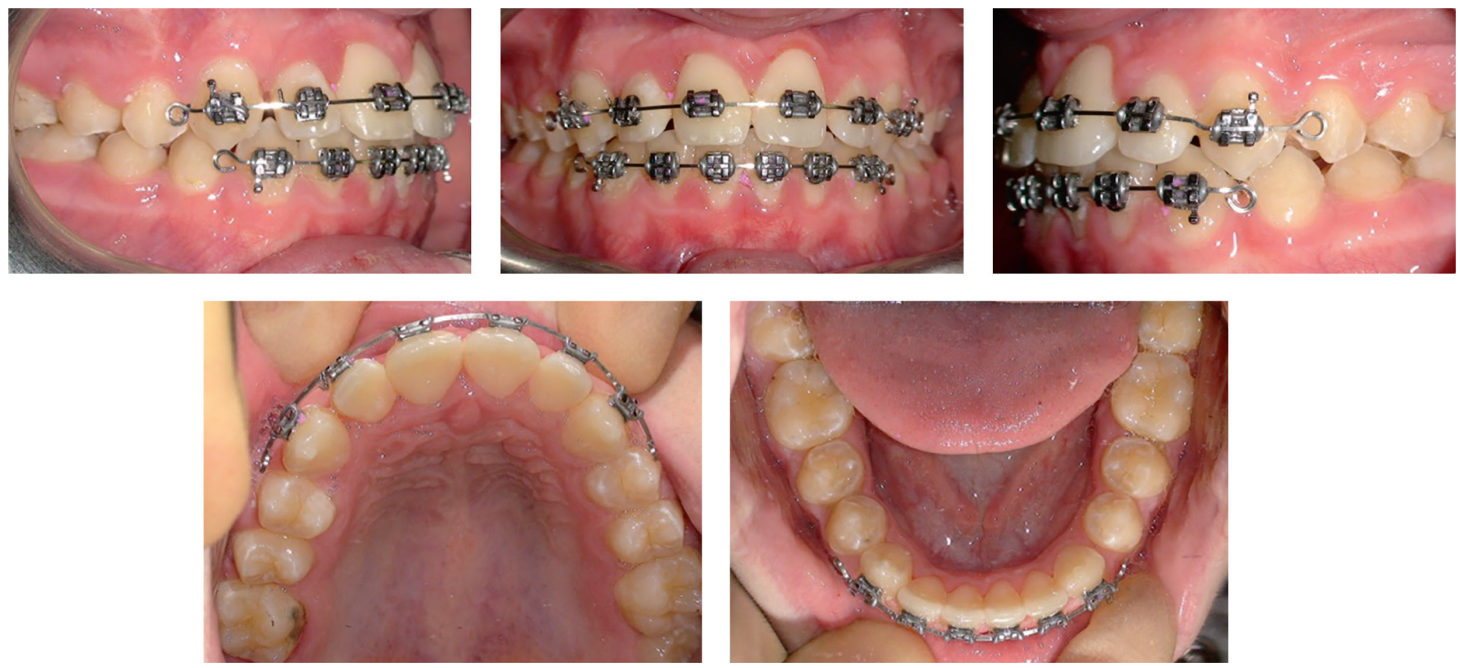

Figure 24

Intraoral View Stage 11 (December 2010).
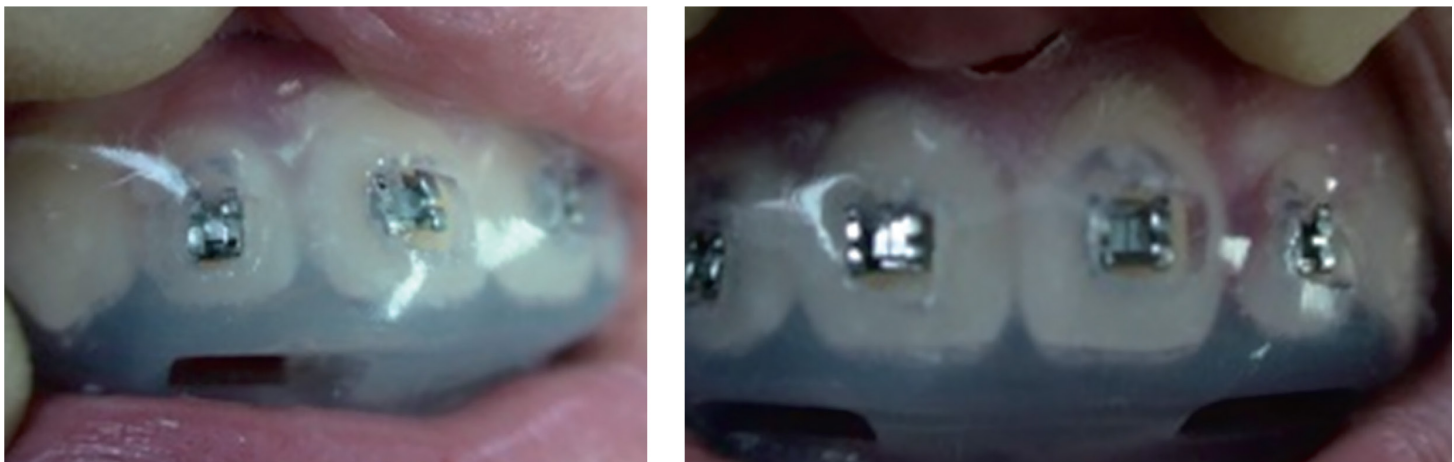

Figure 25

Elastomer in place (January 2011).
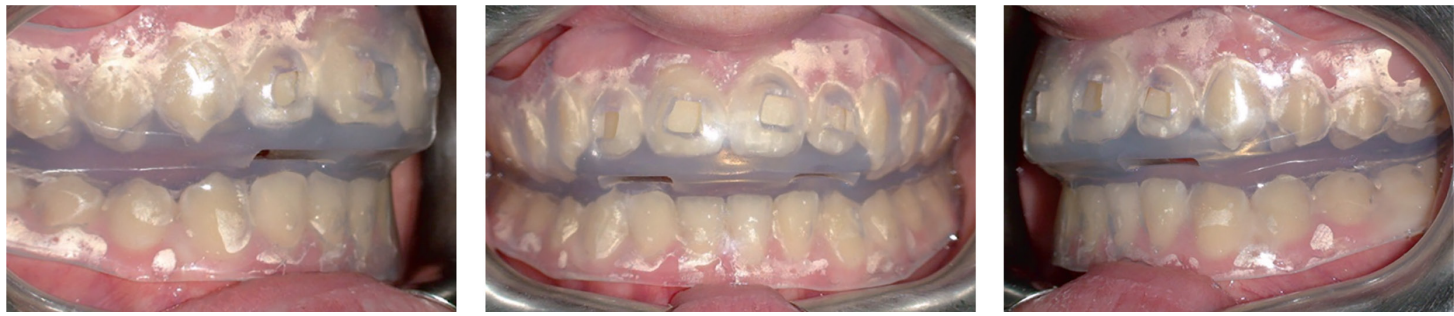

Figure 26

Remove brackets (March 2011). 

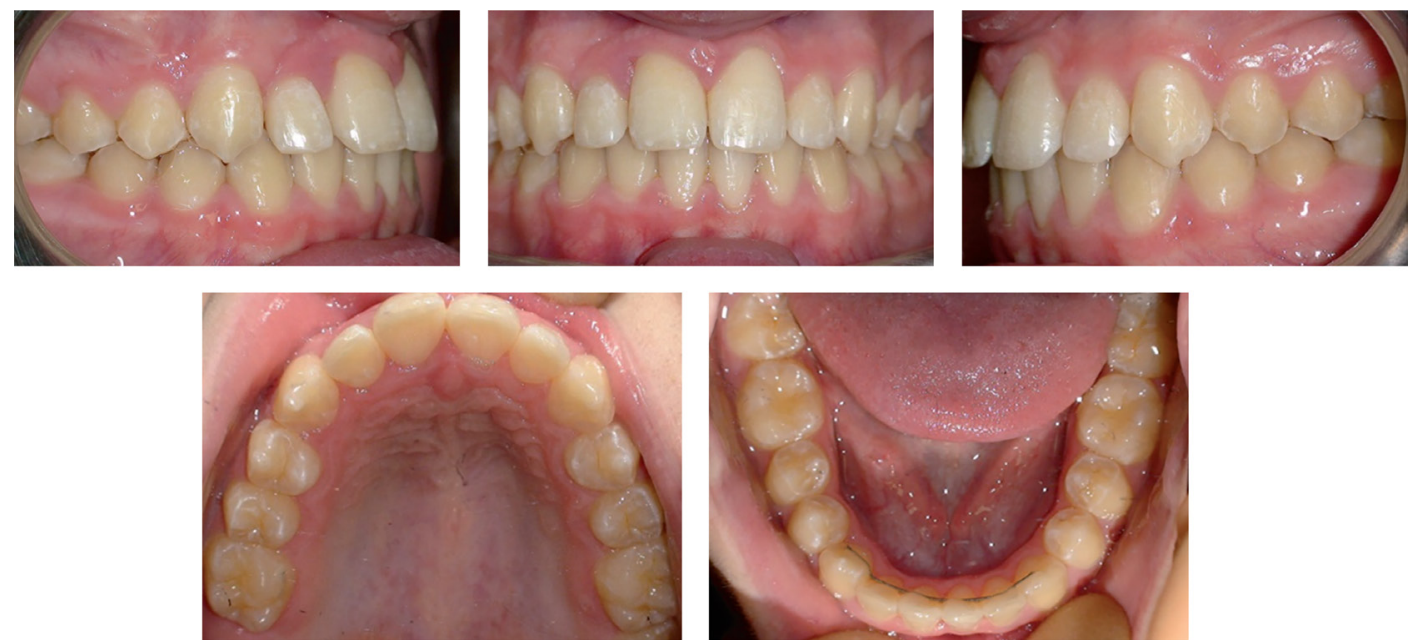

Figure 27

End of treatment.

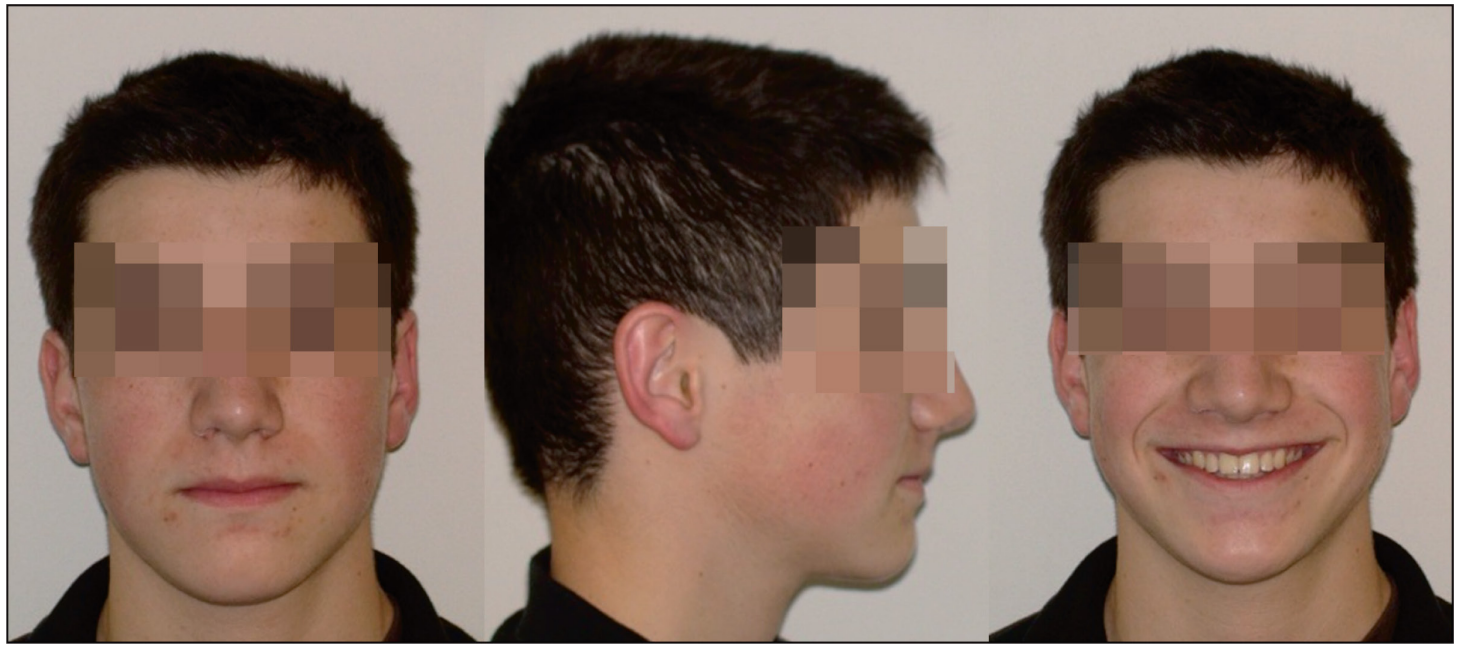

Figure 28

Frontal, Profile and Smile images of the face at the end of treatment. 


\section{DISCUSSION}

Follow-up X-rays show that there is no root resorption, even on 12, which has made a dramatic recovery. However, there remains a slight radicular linguoversion of this tooth. The Harvold triangle at the end of treatment shows a good balance of structures and the teleradiography of the face shows a maxilla with a width of $57.5 \mathrm{~mm}$ (Figs. 29-31).

The objectives set out at the beginning were achieved: Remittance on the arch of 13, 12 and 11, slight in of the upper incisors, correction of the median and slight vestibuloversion of the lower incisors. The quality of the occlusion was ensured by the elastomer (Figs. 32 and 33).

Contention monitoring 4 years after the treatment confirms a good level of stability (Figs. 34 and 35).

At the end of the treatment, the father asked me with a big smile on his face: "Where do we put the implants?"

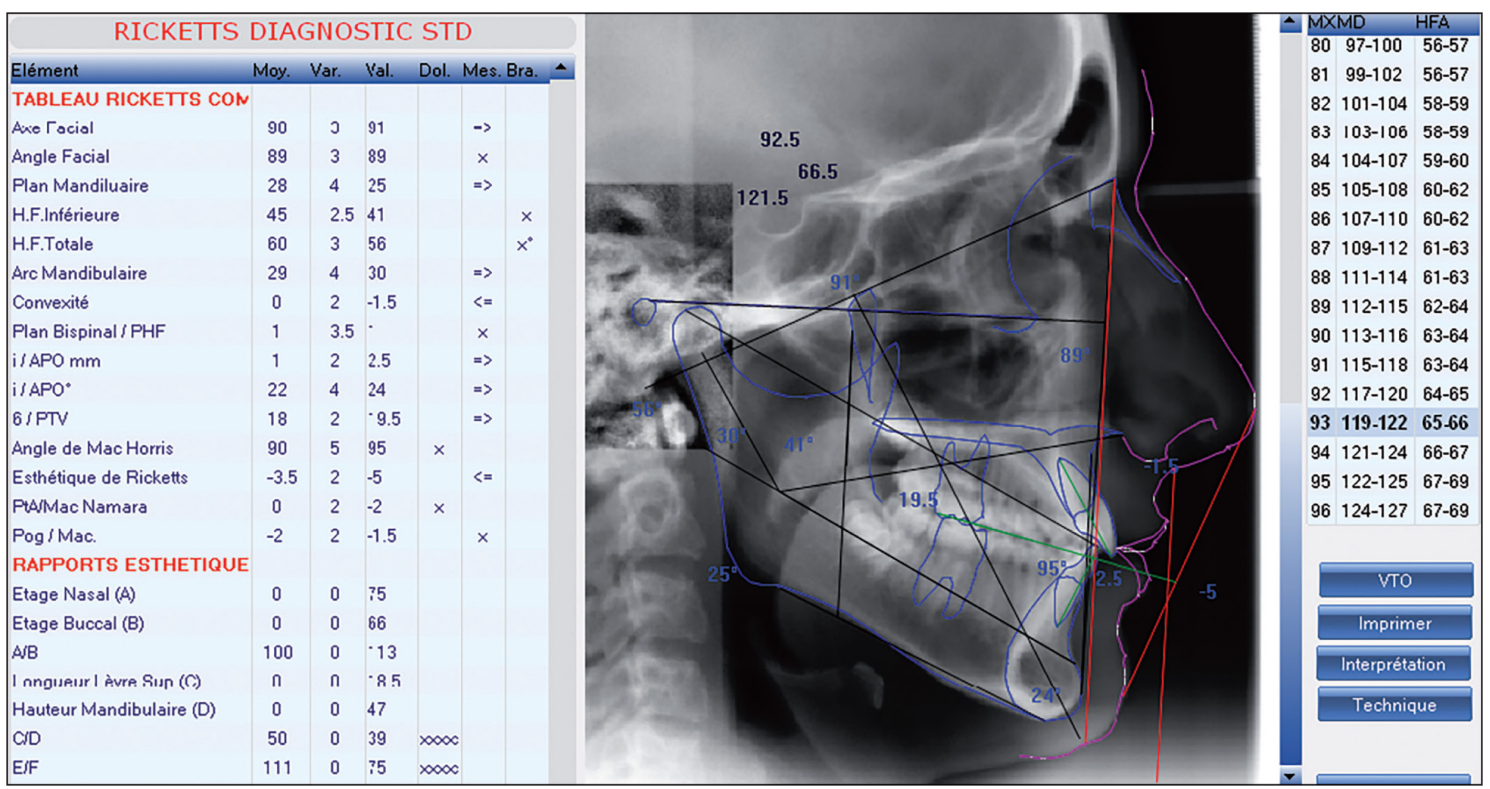

Figure 29

Final Ricketts Cephalometric Profile Analysis. 


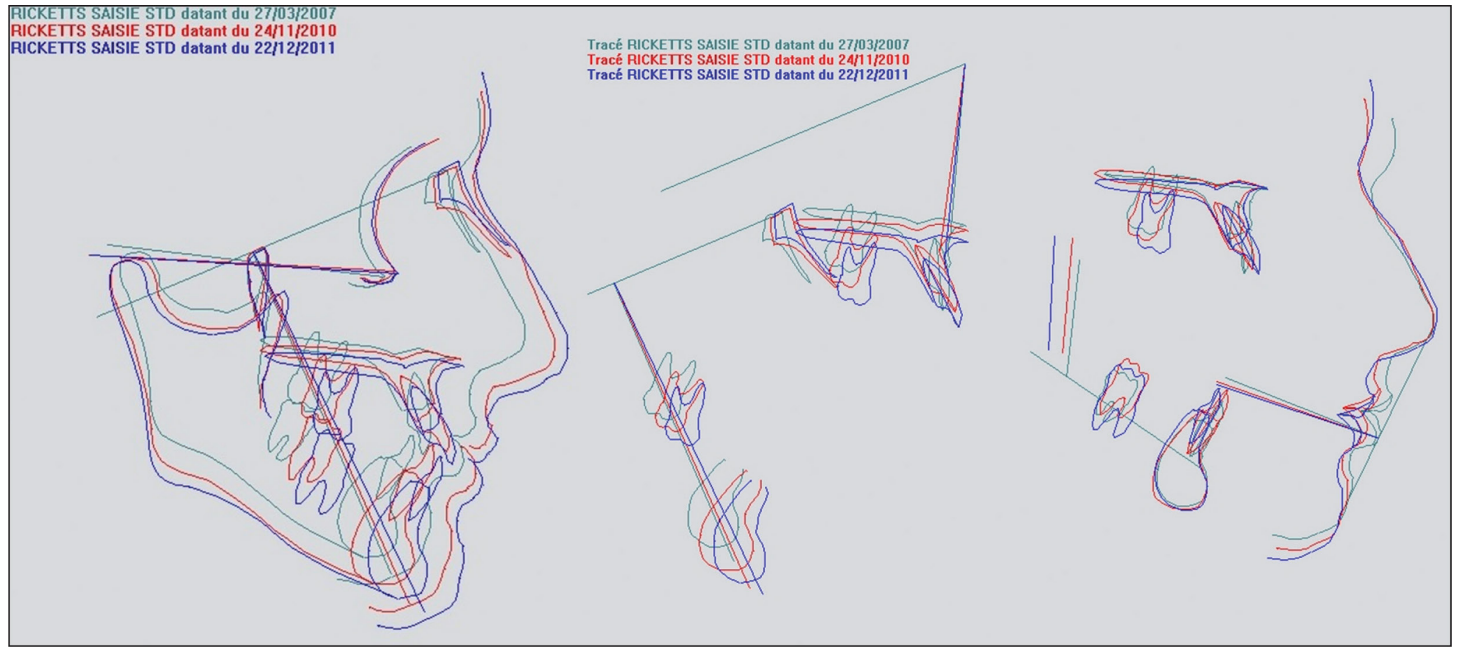

Figure 32

Evaluation of results.
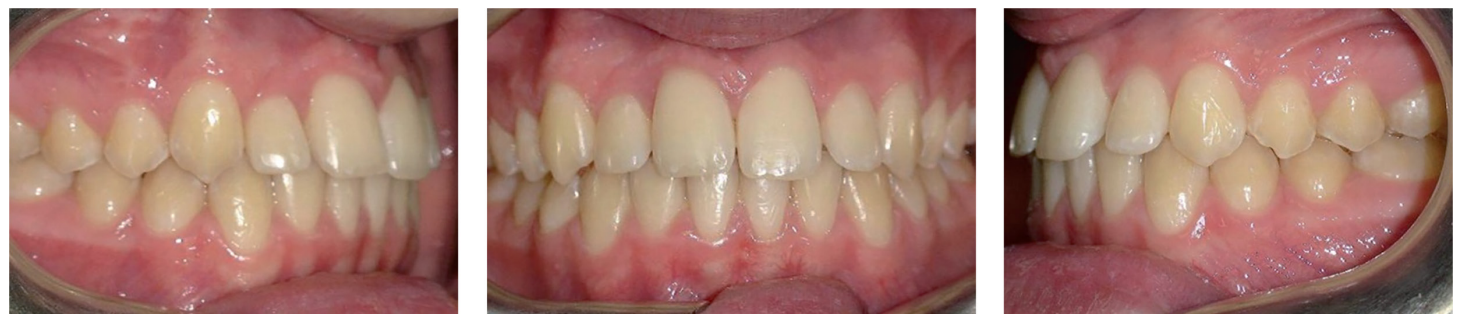

Figure 33

2 years after contention.
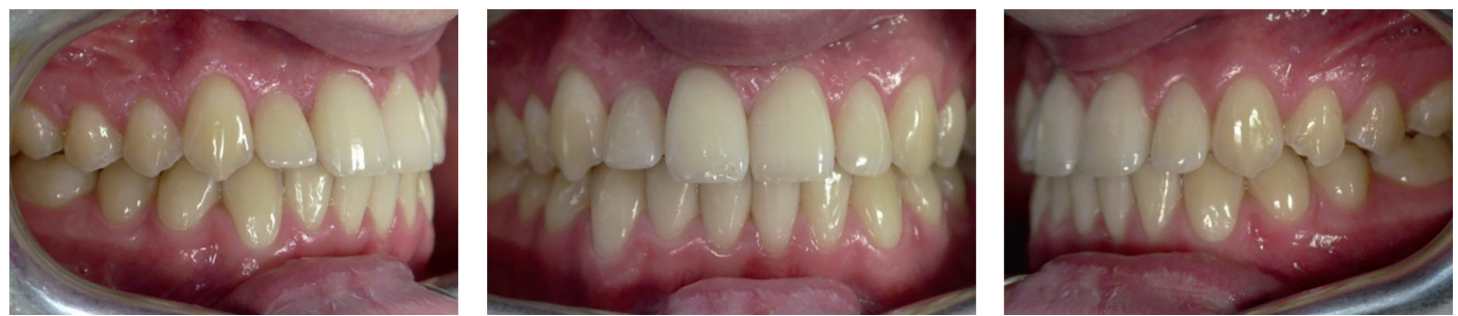

Figure 34

3 years after contention. 


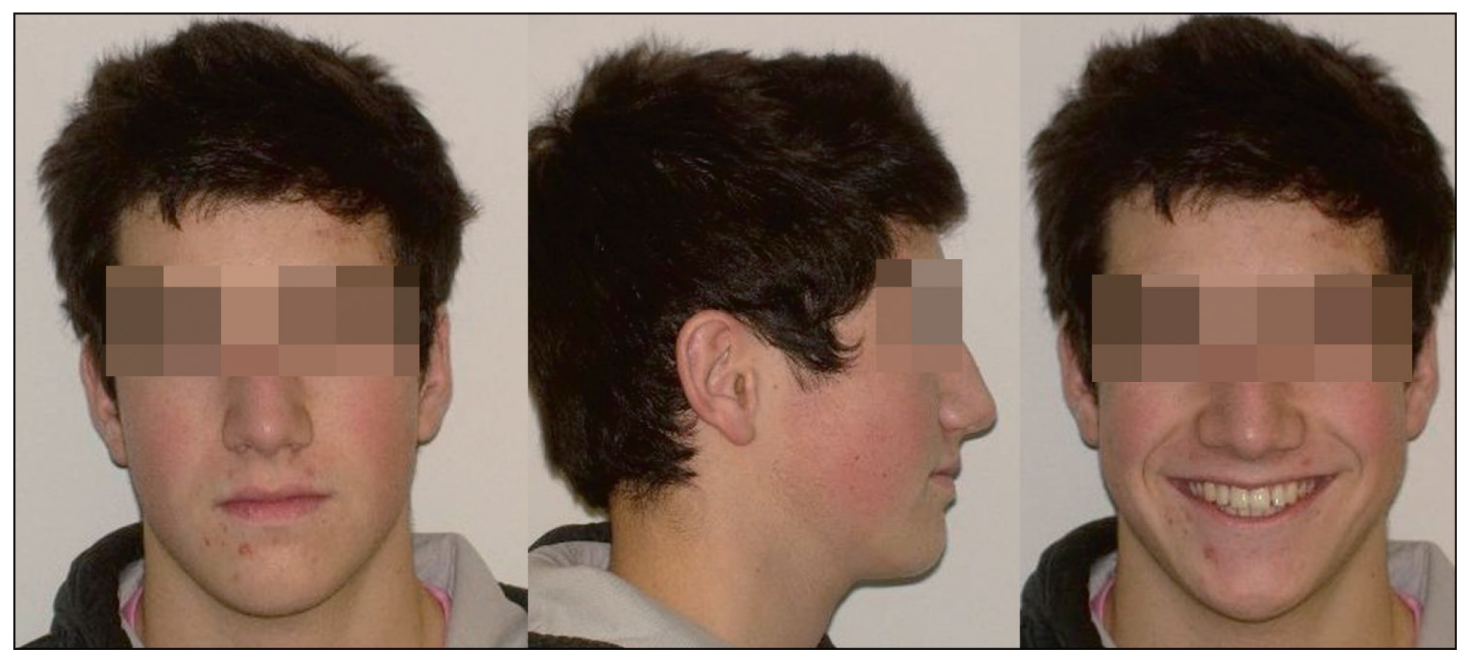

Figure 35

Face 3 years after contention.

\section{CONCLUSION}

The use of light and progressive forces on the impacted teeth allowed them to be placed onto the arch without any apparent root lesions. The segmentation of the mechanics was key to having a control adapted to the various maxillary sectors-in particular, an indi- vidualized base arch with multiple impacted teeth. The three teeth and their environment are perfectly healthy, and the prognosis seems very favorable.

Conflict of Interest: The author states that there is no conflict of interest. 